\title{
A V-EASI-MS Study of the Ugi Reaction Mechanism
}

Vanessa G. Santos, ${ }^{1}$ Thais Regiani, ${ }_{2}^{1}$ Marcos N. Eberlin, ${ }^{1}$ Simon J. Garden, ${ }^{2}$ Fernando H. de Souza Gama, ${ }^{2}$ Leandro Soter de Mariz e Miranda ${ }^{3}$ Rodrigo Octávio Mendonça Alves de Souza

1- ThoMSon Mass Spectrometry Laboratory, State University of Campinas, São Paulo-Br 2- Instituto de

Química, Universidade Federal do Rio de Janeiro, Brazil. 3-Instituto Federal de Educação Ciência e Tecnologia do Rio de Janeiro, Campus Rio de Janeiro; Rio de janeiro; Brazil. 
Excluído: isobaric

\section{INTRODUCTION}

Multicomponent reactions are defined as those where more then two substances react and essencially most of their atoms are incorporated in the product. In the case of the Ugi four component reaction an isocyanide, aldehyde. amine and carboxylic acid react to form a tripeptide. One important characteristic of the multicomponent reaction is the difficulty to elucidate the molecular sequence of events that take place in order to form the products.

Venturi easy ambient sonic-spray ionization (V EASI) 1 is an ambient ionization technique based on the Venturi effect that provides self-pumping and online monitoring of the Ugi reaction giving representative snapshots of the ionic composition of the reaction solution and therefore key information with respect to the mechanism(s). In this study, we have used V-EASI and charged tagged reagents with a remote quaternary ammonium functionality to improve detection of otherwise neutral or zwitterionic species. The model reaction employed 4trimethylammonium benzaldeyde iodide, acetic acid aniline and cyclohexylisocyanide, in equimola quantities and at ambient temperature in methanol,

\section{RESULTS AND DISCUSSION}

After initiation of the reaction, the first sample was analyzed after 10 minutes. At this time the ions detected in the reaction corresponded to the equilibrium involving the formation of the imine. The structures presented in scheme 1 were confirmed by MS/MS experiments on the corresponding ions. The ion $\mathrm{m} / \mathrm{z} 239$ corresponding to the imine was the most intense signal in the spectrum.

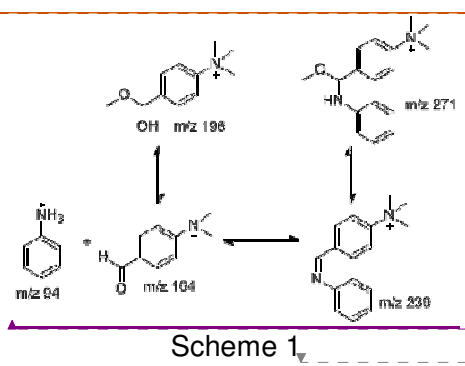

After 2 hours of mixing at ambient temperature an appearance of an jon of $\mathrm{m} / \mathrm{z}$ 408, was detected in the reaction media. This molecular mass is consistent with the acetate presented in scheme 2 as well as with the expected product of the reaction. The MS/MS analysis of this peak reveal a important fragment of $\bar{m} / \bar{z} 223_{n}$ also present in the MS/MS analysis of imine presented in scheme 1. This result indicates the presence the acetate or intermediate before the Mumm rearrangement. However this MS/MS analysis can be representative of a of these

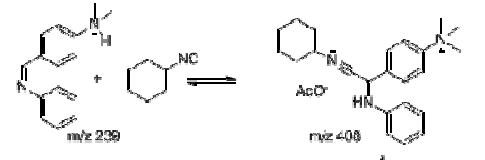

compounds, leading at the present moment to an inconclusive analysis,

Scheme 2

In order to ascertain about the nature of these species in the solution, an MS/MS experiments of the jon of $\mathrm{m} / \bar{z} \overline{4} \mathrm{~B}$ over time will be carried, as well as the synthesis of the product in order to compare the $\bar{M} \bar{S} / \bar{M} S_{-}$spectra.

\section{CONCLUSION}

In the present work important advances towards the

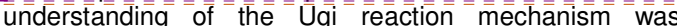
undertaken, however the presence of different isobaric intermediates complicates the interpretation of the data and additional experiments will be performed to overcome these difficulties.

\section{ACKNOWLEDGEMENTS}

\section{QR CNPq}

\section{REFERENCES}

1 Santos, V. G.: Regiani, T.: Dias, F. F. G.: Romäo, W. Jara, J. L. P. Klitzke, C. F.: Coelho, F.: Eberlin, M. N. Venturi Easy Ambient Sonic-Spray lonization. Anal. Chem., 2011, 83 (4).pp 1375-1380

${ }_{2}^{2}$ Ramzi Ait Youcef, Mickael Dos Santos, Sandrine Roussel, Jean-Pierre Baltaze, Nadege tubir-Germain and -Jacques Uziel... - Org. Chem., 2009 74 (11). pp 4318-4323

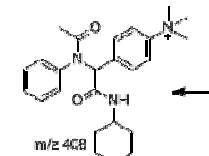

Formatado

Excluído:

Excluído: isobaric

Formatado

Formatado

Excluído: -...analysis

Formatado

Excluído: peak

Formatado

Excluído: 2494

Formatado

Excluído:

Excluído: um

Formatado

Formatado

Excluído: Multicompon

Excluído: ambiemt

Excluído: ambient

Excluído: temperatue

Excluído: temperature

Formatado

Formatado

Excluído: Once the re

Excluído: analysis

Excluído: experiments

Excluído: molecular mass

Excluído: $m / z 239$

Formatado

Formatado

Excluído: peak

Excluído: signal in the spectra.

Formatado

Formatado

Excluído: presented in figure 1

Formatado

Excluído: involving the

Formatado

Excluído: ๆ

Excluído: ๆ

Formatado

Formatado

Formatado

Excluído: peak ...mole

Formatado

Formatado

Formatado 